\title{
High Level Plasmid-Mediated Quinolone Resistance in Clinical Infections at a Tertiary Healthcare Institution in South-West Nigeria
}

Abiodun Ronke Ojewuyi ( $\sim$ ojewuyia@gmail.com )

Bowen University Iwo https://orcid.org/0000-0002-3811-1967

\section{Babatunde Odetoyin}

OAU: Obafemi Awolowo University

Aaron Oladipo Aboderin

OAU/OAUTHC

\section{Research}

Keywords: Plasmids, quinolone resistance, PMQR, Clinical infections

Posted Date: November 11th, 2020

DOI: https://doi.org/10.21203/rs.3.rs-103469/v1

License: (c) (i) This work is licensed under a Creative Commons Attribution 4.0 International License.

Read Full License 


\section{Abstract}

Background Plasmid-mediated quinolone resistance (PMQR) has become a growing clinical concern worldwide. Recent reports from Nigeria revealed that qunolone resistant clinical isolates have become commomplace. However, few reports regarding the prevalence of PMQR are available. Hence, this study aimed to determine the prevalence of $P M Q R$ genes in qunolone resistant clinical isolates from a tertiary care hospital in Nigeria.

Methods This was a cross-sectional hospital based study involving 390 non-repetitive Gram negative bacilli from diverse clinical infections. The isolates were characterized by the Microbact ${ }^{\mathrm{TM}}{ }^{\text {identification }}$ kit and their susceptibility patterns determined by the Kirby-Bauer disc diffusion technique. All quinolone resistant isolates were investigated for the carriage of PMQR genes by multiplex polymerase chain reaction (PCR). Data analysis was with appropriate descriptive and inferential statistics.

Results The isolates were distributed as Escherichia coli $(\mathrm{n}=121 ; 31.0 \%)$, Klebsiella species $(\mathrm{n}=$ $112 ; 28.7 \%)$, Pseudomonas aeruginosa ( $n=59 ; 15.1 \%)$, Proteus species $(n=43 ; 11.0 \%)$, Salmonella species $(n=6 ; 1.3 \%)$ and others. They were commonly resistant to nalidixic (62.6\%), co-amoxiclav (57.7\%); norfloxacin (52.3\%), ofloxacin(52.1\%) and ciprofloxacin(51.0\%), but were least resistant to imipenem; $(n=36 ; 9.2 \%)$. Out of 244 isolates that were resistant to at least one quinolone, $180(73.8 \%)$ harboured one or more PMQR gene with a high prevalence of efflux-mediating determinants (qepA, 22.5\%; oqxAB, $21.1 \%)$, and the aminoglycoside acetyltransferase ( $\left.\operatorname{aac}\left(6^{\prime}\right)-l b-c r, 19.7 \%\right)$. Proportionately low level of target-protecting determinants; $q n r B, 13.2 \%$; $q n r S, 8.7 \%$; $q n r A, 5.9 \%$; $q n r D, 4.5 \%$ and $q n r C, 4.2 \%$ were found in these isolates.

Conclusion There is high level quinolone resistance and wide distribution of PMQR genes in clinical isolates in Nigeria with a preponderance of Efflux-mediating determinants and the aminoglycoside acetyltransferase. This emphasizes the need for regular resistance surveillance and antimicrobial stewardship to guide the appropriate and judicious use of antibiotics.

\section{Background}

Quinolones are synthetic, broad spectrum antibacterial drugs with bactericidal activities against a wide range of bacteria. The mechanism of action is through the arrest of Deoxyribonucleic acid (DNA) replication fork progression by interaction with bacterial topoisomerase II enzymes: DNA gyrase and topoisomerase IV. ${ }^{1}$ Quinolones are often the first line in the treatment of several forms of bacterial infections especially in developing countries, thus their extensive use clinically ${ }^{1}$ and non-clinically in livestock and agriculture. ${ }^{2}$ In the last few decades, there has been a remarkable increase in the overall use of quinolones such as ciprofloxacin and ofloxacin., 4

The common mechanisms of resistance to quinolones reported after discovery of nalidixic acid were chromosomal involving alterations in target enzymes and since quinolones are synthetic antibiotics, it 
was thought that mutations in target genes would be the only mechanisms through which resistance could be acquired because quinolone-resistance genes were not expected to occur in nature. ${ }^{2,5} \mathrm{However}$, the first plasmid-mediated resistance gene in quinolones; qnrA1 was reported in 1998 from a Klebsiella pneumoniae clinical strain. ${ }^{6}$ Since then, more plasmids-transferable resistance mechanisms to quinolones have been identified: $q n r A$, qnrS, qnrB, qnrC, qnrD, qnrE, and $q n r V C .{ }^{2,5-10} \mathrm{Also}$, some other elements like efflux pumps: oqxAB and qepA, with a quinolone modifying enzyme $A a c\left(6^{\prime}\right)-l b-c r$ have also been shown to contribute to quinolone resistance. ${ }^{2,5,6,10-12}$ Studies done earlier in Nigeria reported low level of resistance to the fluoroquinolones among clinical isolates probably because the drugs were not in common use before the expiration of patents for the first generation of these drugs in early $2000 \mathrm{~s} .{ }^{13}$ More recently, there are reports of high level resistance to quinolones in Nigeria as well as neighbouring countries in West Africa. ${ }^{13-20}$ Though, target protection mechanism (qnr proteins) were the first to be discovered, previous studies suggested $\operatorname{aac}\left(6^{\prime}\right)-I b$-cr to be the commonest PMQR gene followed by qepA and the qnr genes ${ }^{11,14}$ and a more recent systematic review of published articles on fluoroquinoloneresistant enteric bacteria in sub-Saharan Africa found a high prevalence of PMQR genes as well as an upregulation in efflux pumps and also the drug-modifying mechanism across several species of bacteria. ${ }^{21}$ In view of the need for continuous antimicrobial resistance surveillance as part of global efforts to contain the emergence and dissemination of antimicrobial resistance, we determined the distribution of PMQR genes in Gram negative bacilli from a tertiary healthcare institution in South-West Nigeria.

\section{Methods And Materials}

\section{Study site}

This study was conducted at the Department of Medical Microbiology and Parasitology of Obafemi Awolowo Teaching Hospitals Complex (OAUTHC) and the Central Science Laboratory, Obafemi Awolowo University (OAU), lle-lfe, Osun State. Approval was obtained from the Research and Ethics Committee of the OAUTHC, lle-lfe for the study (protocol number ERC/2016/01/09). OAUTHC is a first generation Teaching Hospital with about 600 bed complement and a large capacity for out-patients averaging about 220,000 out-patients annually. It was a cross-sectional study with a sample size of 390 non-repetitive isolates. All Gram-negative bacilli isolated from clinical infections at different body sites such as blood, urine, wound and aspirates during the period of study were included in the study while all isolates suspected to be contaminants and isolates from patients without any focus of infection were excluded from the study.

\section{Processing of Specimens}

Blood collected in BACTEC (Becton Dickinson, Belgium) culture bottles were incubated over 24 hrs to 5 days in a semi-automated BACTEC 9050 blood culture machine (Becton Dickinson, Belgium). The blood culture bottles which signalled to be positive were then sub-cultured on $5 \%$ sheep blood agar, chocolate 
agar and MacConkey agar plates. MacConkey agar plates were incubated aerobically while; sheep blood agar and chocolate agar were incubated in $5 \% \mathrm{CO}_{2}$ condition at $37^{\circ} \mathrm{C}$ for $18-24$ hours.

Semi quantitative urine culture was done with a calibrated loop with a loopful $(0.001 \mathrm{~mL})$ of well mixed un-centrifuged urine inoculated onto the surface of cysteine lactose electrolyte deficient medium (CLED). The culture plates were incubated aerobically at $37^{\circ} \mathrm{C}$ for $18-24$ hours. Culture of a single bacterial species from the urine sample at a concentration of $10^{5} \mathrm{cfu} / \mathrm{ml}$ associated with microscopy findings of > 10 white blood cells (WBCs) per high power field was taken as significant bacteriuria. ${ }^{22}$

Cerebrospinal fluid (CSF) samples were examined macroscopically and microscopically, a direct Gram staining was done on the specimen and then plated immediately on blood agar, MacConkey and chocholate agar. MacConkey agar plates were incubated aerobically while; blood agar and chocolate agar were incubated in $5 \% \mathrm{CO}_{2}$ condition at $37^{\circ} \mathrm{C}$ for $18-24$ hours.

Sputum or tracheal aspirates collected in sterile screw-top container were processed immediately. Culture was on blood and MacConkey agar and incubation was under aerobic for MacConkey plates and $5 \% \mathrm{CO}_{2}$ enriched atmosphere for blood agar plates, both at $37^{\circ} \mathrm{C}$ for $18-24$ hours. Stool sample brought to the laboratory in a clean, leak-proof container were also processed and routine culture included for Salmonella species, Shigella species, Vibrio species and Escherichia coli 0157:H7. The samples were cultured on Deoxycholate citrate agar, MacConkey agar, Selenite-F or thiosulfate-citrate-bile-salts-sucrose agar as indicated and incubated aerobically at $37^{\circ} \mathrm{C}$ for $18-24$ hours.

A direct Gram was done on specimens on swabs, including ear, eye and wound swabs and were cultured immediately on blood and MacConkey agar. A direct Gram was done on wound biopsy and aspirates, and subsequently cultured on processed blood and MacConkey agar. Incubation was under aerobic condition at $37^{\circ} \mathrm{C}$ for $18-24$ hours.

\section{Identification of Bacterial isolates}

Identification of the isolates was by colonial morphology on agar plate, Gram staining, then, biochemical tests such as citrate utilization, urease test, reaction on triple sugar iron agar, indole production, oxidase and motility tests were carried out on the Gram negative bacilli. ${ }^{23,}{ }^{24}$ Also, Microbact $^{\text {TM }}$ GNB 24E was used in identification of oxidase-positive, nitrate negative, glucose non-fermenters and GNB 12E was used in identification of oxidase-negative, nitrate-positive, glucose fermenters. Interpretation of the result was by use of Microbact ${ }^{\text {TM }}$ (Oxoid, England) identification software package, version 2009. All test were done according to the recommendations of Clinical and Laboratory Standards Institute (CLSI). ${ }^{25}$

\section{Antimicrobial susceptibility testing}

Antimicrobial susceptibility testing was done by the modified Kirby-Bauer disc diffusion method. ${ }^{26}$ Mueller-Hinton agar plates were incubated for 18-24 hours after inoculation with test organisms and placement of antibiotic discs. All isolated Gram negative bacilli were tested against nalidixic acid $(30 \mu \mathrm{g})$, ciprofloxacin $(5 \mu \mathrm{g})$, norfloxacin $(10 \mu \mathrm{g})$, ofloxacin $(5 \mu \mathrm{g})$, ampicillin $(10 \mu \mathrm{g})$, ceftazidime $(30 \mu \mathrm{g})$, 
cefotaxime $(30 \mu \mathrm{g})$, cefepime $(30 \mu \mathrm{g})$, co-amoxiclav $(20 / 10 \mu \mathrm{g})$, gentamicin $(10 \mu \mathrm{g})$, imipenem $(10 \mu \mathrm{g})$, and nitrofurantoin $(300 \mu \mathrm{g})$ which was used for urinary isolates only. The results were interpreted according to Clinical and Laboratory Standards Institute guidelines and WHONET software version 5.6.

\section{ESBL and AmpC $\beta$-lactamase Resistance testing}

All the Gram negative bacilli identified were phenotypically screened for extended-spectrum betalactamases (ESBLs) and AmpC $\beta$-lactamase. The phenotypic confirmatory test for ESBLs was done using combined disks of cefotaxime-clavulanate $(30 / 10 \mu \mathrm{g})$ and cefotaxime alone, and ceftazidimeclavulanate $(30 / 10 \mu \mathrm{g})$ and ceftazidime alone. $A \geq 5 \mathrm{~mm}$ increase in a zone of inhibition for either of the two third-generation cephalosporins tested in combination with clavulanate versus its zone of inhibition when tested alone was reported as ESBLs-producing organisms according to the recommendations of Clinical and Laboratory Standards Institute (CLSI). ${ }^{25}$

Screening for AmpC $\beta$-lactamase was by use of AmpC Disk method ${ }^{27}$ : A lawn was made on MuellerHinton agar plate from a broth containing E. coli ATCC 25922 standardized to 0.5 McFarland. Distilled water of about $20 \mu \mathrm{l}$ was used to moisten a sterile filter paper disk $(6 \mathrm{~mm})$ containing Tris-EDTA. Up to five colonies of test organism were transferred on the filter paper. Thereafter, a cefoxitin $(30 \mu \mathrm{g})$ disk was placed on inoculated media and the inoculated filter paper disk was placed beside the cefoxitin disk; the two almost touching. This set-up was incubated overnight at $37^{\circ} \mathrm{C}$. A flattening of the zone of inhibition of cefoxitin in the vicinity of test disk was interpreted as a positive result; an undistorted zone of inhibition was taken as negative result.

\section{Determination of presence of PMQR}

Plasmid DNA was extracted from pure colonies of isolates which were resistant to quinolones using the boiling method. Two colonies of overnight grown bacteria were put in Eppendorf tubes containing $100 \mu \mathrm{l}$ of sterile water and boiled for 10 minutes in a water bath, then centrifuged for 10 minutes at $13000 \mathrm{rpm}$. The resulting DNA suspension from the supernatant was used as a template DNA in subsequent polymerase chain reaction (PCR) based detection. All the primers used were commercially synthesized by Inqaba biotechnical Industries (Pty) Ltd, South Africa.

The multiplex PCR protocol developed for PMQR by Cesiekzuk et. al. ${ }^{28}$ was used in this study. All isolates were screened twice for the PMQR genes in two sets using specific primers for $q n r A$, qnrB, qnrS, qnrC, $q n r D$ and also for $\operatorname{aac}\left(6^{\prime}\right)-l b-c r, q e p A$, and oqxAB. For the first set made up of $q n r A$, qnrC, qnrB, qepA, amplification conditions were as follows: an initial denaturation at $94^{\circ} \mathrm{C}$ for $4 \mathrm{~min} ; 30$ cycles of $94{ }^{\circ} \mathrm{C}$ for $30 \mathrm{~s}$, optimized annealing temperature $55^{\circ} \mathrm{C}$ for $30 \mathrm{~s}$ and $72{ }^{\circ} \mathrm{C}$ for $1 \mathrm{~min}$; followed by a final extension at $72{ }^{\circ} \mathrm{C}$ for 5 min.

The second set included $q n r D$, $q n r S$, aac $\left(6^{\prime}\right)-I b-c r$, oqxAB, and the amplification condition was initial denaturation at $94^{\circ} \mathrm{C}$ for 4 min, followed by 30 cycles of denaturation at $94^{\circ} \mathrm{C}$ for $45 \mathrm{~s}$, annealing at $55^{\circ} \mathrm{C}$ for $45 \mathrm{~s}$, extension at $72{ }^{\circ} \mathrm{C}$ for $1 \mathrm{~min}$ then a final extension at $72{ }^{\circ} \mathrm{C}$ for $3 \mathrm{~min}$. 
Each amplicon $(10 \mu \mathrm{L})$ was electrophoresed on a $1.5 \%$ agarose gel pre stained with $0.5 \mu \mathrm{g} / \mathrm{mL}$ Ethidium bromide in 1X Tris-Borate-EDTA (TBE) buffer and viewed with a UVitec transilluminator (Avebury, Cambridge UK). The positions of the amplified product were estimated by the position of 100 base pair molecular weight marker (Bio Lab).

\section{Sequencing}

Amplimers resulting from PCR reactions for two isolates found to have all the targets were sequenced at Inqaba biotechnical Industries (Pty) Ltd. South Africa, to confirm their identities. The resulting forward and reverse sequences were aligned with Blast multiple alignment tool at site http://www.ncbi.nlm.nih.gov. Sequences were accepted when it corresponds with known PMQR sequences in Blast data base. A repeat PCR was then done and isolates with the sequenced genes used as controls.

\section{Data analysis and statistical techniques}

The data was analysed using the IBM Statistical Package for Social Sciences (SPSS) version 20 (IBM, Armonk, NY, USA) and WHONET software version 5.6. Categorical variables were summarized and presented on frequency tables with simple proportions and charts as appropriate. Inferential bivariate analyses were performed using Chi-square and Fishers exact test. The level of statistical significance was determined at p-values less than 0.05 .

\section{Results}

\section{Patient characteristics and Isolates distribution in clinical infections}

A total of 390 non-repetitive Gram-negative bacilli isolates were isolated from clinical specimens of 382 patients between December 2016 and August 2017; 256 patients were on admission while 126 others were out-patients. There were 211 males and 171 females, with a wide age distribution between 1 and 90 years. The average age distribution was between 31-40 years. More than half of the isolates $(n=201$; $51.5 \%)$ were from patients with urinary tract infections, 131 (34.3\%) isolates were from wound infections, and $47(12.1 \%)$ isolates were obtained from blood of patients with sepsis while $8(2.1 \%)$ isolates were from patients with other infections including arthritis and meningitis (Table 1). 
Table 1. Distribution of the Isolates from Clinical Infections

\begin{tabular}{llllll}
\hline & $\begin{array}{l}\text { Urinary Tract } \\
\text { Infections }\end{array}$ & $\begin{array}{l}\text { Blood } \\
\text { Stream } \\
\text { Infections }\end{array}$ & $\begin{array}{l}\text { Wound } \\
\text { Infections }\end{array}$ & $\begin{array}{l}\text { Infection at } \\
\text { Other Sites }\end{array}$ & $\begin{array}{l}\text { Total } \\
\text { (\%) }\end{array}$ \\
\hline Acinetobacter baumanii & $0(0.0)$ & $1(33.3)$ & $2(66.7)$ & $0(0.0)$ & $3(100.0)$ \\
Acinetobacter iwofii & $0(0.0)$ & $1(50.0)$ & $1(50.0)$ & $0(0.0)$ & $2(100.0)$ \\
Citrobacter freundii & $2(50.0)$ & $0(0.0)$ & $2(50.0)$ & $0(0.0)$ & $4(100.0)$ \\
Cronobacter sakazaki & $0(0.0)$ & $0(0.0)$ & $1(100.0)$ & $0(0.0)$ & $1(100.0)$ \\
Edwasiella tarda & $0(0.0)$ & $0(0.0)$ & $1(100.0)$ & $0(0.0)$ & $1(100.0)$ \\
Enterobacter aerogenes & $2(66.7)$ & $0(0.0)$ & $0(0.0)$ & $1(33.3)$ & $3(100.0)$ \\
Enterobacter agglomerans & $1(50.0)$ & $0(0.0)$ & $1(50.0)$ & $0(0.0)$ & $2(100.0)$ \\
Enterobacter cloacae & $9(69.2)$ & $1(7.7)$ & $2(15.4)$ & $1(7.7)$ & $13(100.0)$ \\
Enterobacter gergovae & $2(28.6)$ & $3(42.9)$ & $2(28.6)$ & $0(0.0)$ & $7(100.0)$ \\
Escherichia coli & $88(72.7)$ & $7(5.8)$ & $24(19.8)$ & $2(1.7)$ & $121(100.0)$ \\
Hafnia alvei & $0(0.0)$ & $3(75.0)$ & $1(25.0)$ & $0(0.0)$ & $4(100.0)$ \\
Klebsiella oxytoca & $22(57.9)$ & $3(7.9)$ & $12(31.6)$ & $1(2.8)$ & $38(100.0)$ \\
Klebsiella pneumonia & $35(57.9)$ & $12(16.2)$ & $26(35.1)$ & $1(1.4)$ & $74(100.0)$ \\
Morganella morganii & $1(100.0)$ & $0(0.0)$ & $0(0.0)$ & $0(0.0)$ & $1(100.0)$ \\
Proteus mirabilis & $10(31.2)$ & $4(12.5)$ & $17(53.1)$ & $1(3.1)$ & $32(100.0)$ \\
Proteus vulgaris & $3(27.3)$ & $1(9.1)$ & $7(63.6)$ & $0(0.0)$ & $11(100.0)$ \\
Providenchia rettgeri & $2(100.0)$ & $0(0.0)$ & $0(0.0)$ & $0(0.0)$ & $2(100.0)$ \\
Providenchia stuatti & $2(100.0)$ & $0(0.0)$ & $0(0.0)$ & $0(0.0)$ & $2(100.0)$ \\
Pseudomonans aeruginosa & $21(35.6)$ & $3(5.1)$ & $35(59.3)$ & $0(0.0)$ & $59(100.0)$ \\
Salmonella Typhi & $0(0.0)$ & $5(100.0)$ & $0(0.0)$ & $0(0.0)$ & $5(100.0)$ \\
Salmonella Pullorum & $0(0.0)$ & $1(100.0)$ & $0(0.0)$ & $0(0.0)$ & $1(100.0)$ \\
Serratia marscescence & $1(100.0)$ & $0(0.0)$ & $0(0.0)$ & $0(0.0)$ & $1(100.0)$ \\
Stenotrophomonas maltophila & $0(0.0)$ & $2(66.7)$ & $0(0.0)$ & $1(33.3)$ & $3(100.0)$ \\
Total (\%) & & & & & \\
& $201(52 \%)$ & $47(12 \%)$ & $134(34 \%)$ & $8(2 \%)$ & $390(100)$ \\
\hline & & & & & \\
\hline
\end{tabular}

\section{Antimicrobial resistance profile of isolates}

The isolates were commonly resistant to nalidixic acid ( $n=244 ; 62.6 \%)$, norfloxacin $(n=204 ; 52.3 \%)$, ofloxacin ( $n=203 ; 52.1 \%)$, ciprofloxacin ( $n=199 ; 51.0 \%)$, ampicillin ( $n=137 ; 35.1 \%)$, cefotaxime $(n=181$; $46.4 \%)$ and co-amoxiclav $(n=168 ; 50.8 \%)$ but were least resistant to imipenem $(n=36 ; 9.2 \%)$ (Table 2$)$. 


\begin{tabular}{|c|c|c|c|c|c|c|c|c|c|c|c|c|}
\hline & \multicolumn{4}{|c|}{ QUINOLONES } & \multicolumn{8}{|c|}{ OTHER ANTIMICROBIALS } \\
\hline & NAL (\%) & CIP (\%) & OFX (\%) & NOR (\%) & $\operatorname{AMC}(\%)$ & CFX $(\%)$ & CEF (\%) & IMI (\%) & $\operatorname{AMP}(\%)$ & FEP (\%) & GEN (\%) & ${ }^{*}$ NIT $(\%)$ \\
\hline Escherichia coli & $84(69.4)$ & $76(62.8)$ & $76(62.8)$ & $76(63.6)$ & $65(53.7)$ & $35(28.9)$ & $52(43.0)$ & $3(2.5)$ & $86(71.1)$ & $29(24.0)$ & $46(38.0)$ & $7(8.0)$ \\
\hline Klebsiellaspp & $72(64.3)$ & $58(51.8)$ & $60(53.6)$ & $60(54.5)$ & $65(58.0)$ & $51(45.5)$ & $59(52.7)$ & $5(5.4)$ & - & $35(31.2)$ & $56(50.0)$ & $22(38.6)$ \\
\hline Enterobacter & $12(48.0)$ & $10(40.0)$ & $10(40.0)$ & $10(40.0)$ & $15(60.0)$ & $12(48.0)$ & $12(48.0)$ & $4(16.0)$ & $17(68.0)$ & $10(40.0)$ & $12(48.0)$ & $3(21.4)$ \\
\hline spp & $47(79.7)$ & $31(52.5)$ & $34(57.6)$ & $34(57.6)$ & - & $27(45.8)$ & $41(69.5)$ & $20(33.9)$ & - & $31(52.5)$ & $33(55.9)$ & $15(71.4)$ \\
\hline P.aeruginosa & $16(37.2)$ & $14(32.6)$ & $14(32.6)$ & $14(32.6)$ & $12(27.9)$ & $9(20.9)$ & $8(18.6)$ & $1(2.3)$ & $18(41.9)$ & $5(11.6)$ & $7(16.3)$ & $5(38.5)$ \\
\hline Proteus spp & $3(60.0)$ & $3(60.0)$ & $3(60.0)$ & $2(40.0)$ & $3(60.0)$ & $3(60.0)$ & $3(60.0)$ & $2(40.0)$ & $4(80.0)$ & $3(60.0)$ & $2(40.0)$ & $0(0.0)$ \\
\hline Acinetobacter & $1(25.0)$ & $1(25.0)$ & $0(0.0)$ & $1(25.0)$ & $0(0.0)$ & $0(0.0)$ & $0(0 / 0)$ & $0(0.0)$ & $2(50.0)$ & $0(0.0)$ & $1(25.0)$ & $0(0.0)$ \\
\hline Citrobacter & $1(16.7)$ & $1(16.7)$ & $1(16.7)$ & $1(16.7)$ & $1(16.7)$ & $0(0.0)$ & $0(0.0)$ & $0(0.0)$ & $1(16.7)$ & $0(0.0)$ & $0(0.0)$ & $0(0.0)$ \\
\hline Salmonella & $1(25.0)$ & $1(25.0)$ & $1(25.0)$ & $1(25.0)$ & $2(50.0)$ & $2(50.0)$ & $2(50.0)$ & $0(0.0)$ & $2(50.0)$ & $1(25.0)$ & $1(25.0)$ & $0(0.0)$ \\
\hline Hafnia alvei & $3(75.0)$ & $2(50.0)$ & $2(50.0)$ & $2(50.0)$ & $2(50.0)$ & $1(25.0)$ & $2(5.0)$ & $1(25.0)$ & $3(75.0)$ & $1(25.0)$ & $1(25.0)$ & $2(50.0)$ \\
\hline Providencia & $2(66.7)$ & $1(33.3)$ & $0(0.0)$ & $1(33.3)$ & $1(33.3)$ & $1(33.3)$ & $0(0.0)$ & - & $1(33.3)$ & $0(0.0)$ & $0(0.0)$ & $0(0.0)$ \\
\hline S.maltophilia & $1(100.0)$ & $1(100.0)$ & $1(100.0)$ & $1(100.0)$ & $1(100.0)$ & $0(0.0)$ & $1(100.0)$ & $0(0.0)$ & $1(33.3)$ & $0(0.0$ & $0(0.0)$ & $0(0.0)$ \\
\hline E.tarda & $0(0.0)$ & $0(0.0)$ & $0(0.0)$ & $0(0.0)$ & $1(100.0)$ & $0(0.0)$ & $1(100.0)$ & $0(0.0)$ & $1(100.0)$ & $0(0.0)$ & $0(0.0)$ & $0(0.0)$ \\
\hline S.marcescence & $0(0.0)$ & $0(0.0)$ & $0(0.0)$ & $0(0.0)$ & $0(0.0)$ & $0(0.0)$ & $0(0.0)$ & $0(0.0)$ & $0(0.0)$ & $0(0.0)$ & $0(0.0)$ & $0(0.0)$ \\
\hline C.sakazakii & $1(100.0)$ & $0(0.0)$ & $1(100.0)$ & $1(100.0)$ & $0(0.0)$ & $0(0.0)$ & $0(0.0)$ & $0(0.0)$ & $1(100.0)$ & $0(0.0)$ & $0(0.0)$ & $1(100.0)$ \\
\hline M.morganii & & & & & & & & & & & & \\
\hline Total no of & 244 & 199 & 203 & 204 & 168 & 141 & 181 & 36 & 137 & 115 & 159 & 55 \\
\hline
\end{tabular}

NAL: Nalidixic acid, CIP: Ciprofloxacin, OFX: Ofloxacin, NOR: Norfloxacin, AMC:Co- Amoxiclav, CFX:Ceftaxidime, CEF: Cefotaxime, IMI: Imipenem, AMP: Ampicillin, FEP: Cefepime, GEN: Gentamicin, NIT:Nitrofuraitoin. Note: Nitrofuraitoin used for U rinary isolate only. ?Not used for Pseudomonas aeruginosa. Not used for Pseudomonas aeruginosa and Klebsiella spp

\section{Distribution of PMQR genes in the Isolates}

Two hundred and forty four isolates were resistant to at least one quinolone, 180 (73.8\%) of these harboured at least one PMQR gene; mostly efflux pump determinants qepA (22.5\%) and oqxAB (21.1\%), others were $\operatorname{aac}\left(6^{\prime}\right)-\operatorname{lb}$-cr $(19.7 \%)$, qnrB (13.2\%), qnrS (8.7\%), qnrA (5.9\%), qnrD (4.5\%), and $\operatorname{qnrC}(4.2 \%)$ (Table 3). The PMQR genes were distributed across isolates occurring either singly or in combinations in all quinolone-resistant isolates of E.coli, Klebsiella spp. and P. aeruginosa. All but one PMQR gene (qnrA) were found evenly distributed in isolates of Enterobacter spp., the salmonella isolate found to be resistant to quinolone had only the efflux pump oqxAB. (Table 3 ). 
Table 3. Distribution of the plasmid-mediated quinolone resistance genes among the quinolone-resistant isolates

\begin{tabular}{|c|c|c|c|c|c|c|c|c|c|c|}
\hline $\begin{array}{l}\text { Quinolone resistant } \\
\text { isolates }(n=244)\end{array}$ & $\begin{array}{l}\text { No of } \\
\text { Quinolone } \\
\text { resistant } \\
\text { isolates }\end{array}$ & $\begin{array}{l}\text { No of } \\
\text { detected } \\
\text { PMQR } \\
\text { genes }^{\text {s }}\end{array}$ & $\begin{array}{l}\text { QnrA } \\
(\%)\end{array}$ & QnrB (\%) & $\begin{array}{l}\text { QnrC } \\
(\%)\end{array}$ & $\begin{array}{l}\text { QnrD } \\
(\%)\end{array}$ & $\begin{array}{l}\text { QnrS } \\
(\%)\end{array}$ & QepA (\%) & $\begin{array}{l}O q \times A B \\
(\%)\end{array}$ & $\begin{array}{l}A a c\left(6^{\prime}\right)-l b-c r \\
(\%)\end{array}$ \\
\hline E. coli & 84 & 133 & $5(6.0)$ & $19(22.0)$ & $4(4.8)$ & $4(4.8)$ & $16(19)$ & $27(32.1)$ & $25(29.8)$ & $33(39.3)$ \\
\hline Klebsiellaspp & 72 & 130 & $9(12.5)$ & $18(25.0)$ & $2(2.8)$ & $3(4.2)$ & $7(9.7)$ & $34(47.2)$ & $37(51.4)$ & $20(27.8)$ \\
\hline Enterobacter spp & 12 & 19 & $0(0.0)$ & $4(33.3)$ & $2(16.7)$ & $1(8.3)$ & $2(16.7)$ & $4(33.3)$ & $3(25.0)$ & $3(25.0)$ \\
\hline P. aeruginosa & 47 & 48 & $5(10.6)$ & $3(6.4)$ & $6(12.8)$ & $4(8.5)$ & $5(10.6)$ & $7(14.9)$ & $6(12.8)$ & $12(25.5)$ \\
\hline Proteus spp & 16 & 10 & $1(6.2)$ & $1(6.2)$ & $0(0.0)$ & $3(18.8)$ & $0(0.0)$ & $4(25.0)$ & $1(6.2)$ & $0(0.0)$ \\
\hline Acinetobacter spp & 3 & 2 & $0(0.0)$ & $0(0.0)$ & $0(0.0)$ & $0(0.0)$ & $1(33.3)$ & $0(0.0)$ & $1(33.3)$ & $0(0.0)$ \\
\hline C. freundii & 1 & 3 & $0(0.0)$ & $1(100.0)$ & $0(0.0)$ & $0(0.0)$ & $0(0.0)$ & $1(100.0)$ & $0(0.0)$ & $1(100.0)$ \\
\hline Salmonella spp & 1 & 1 & $0(0.0)$ & $0(0.0)$ & $0(0.0)$ & $0(0.0)$ & $0(0.0)$ & $0(0.0)$ & $1(100.0)$ & $0(0.0)$ \\
\hline Providencia spp & 3 & 6 & $0(0.0)$ & $1(33.3)$ & $1(33.3)$ & $1(33.3)$ & $0(0.0)$ & $2(66.7)$ & $1(33.3)$ & $0(0.0)$ \\
\hline S. maltophilia & 2 & 2 & $1(50.0)$ & $0(0.0)$ & $0(0.0)$ & $0(0.0)$ & $0(0.0)$ & $0(0.0)$ & $0(0.0)$ & $1(50.0)$ \\
\hline M. morganii & 1 & 1 & $0(0.0)$ & $0(0.0)$ & $0(0.0)$ & $0(0.0)$ & $0(0.0)$ & $1(100.0)$ & $0(0.0)$ & $0(0.0)$ \\
\hline E. tarda & 1 & 0 & $0(0.0)$ & $0(0.0)$ & $0(0.0)$ & $0(0.0)$ & $0(0.0)$ & $0(0.0)$ & $0(0.0)$ & $0(0.0)$ \\
\hline Hafnia alvei & 1 & 0 & $0(0.0)$ & $0(0.0)$ & $0(0.0)$ & $0(0.0)$ & $0(0.0)$ & $0(0.0)$ & $0(0.0)$ & $0(0.0)$ \\
\hline $\begin{array}{l}\text { Total } \\
(\%)\end{array}$ & 244 & 355 & $\begin{array}{l}21 \\
(5.9)\end{array}$ & $47(13.2)$ & $15(4.2)$ & $16(4.5)$ & $\begin{array}{l}31 \\
(8.7)\end{array}$ & $\begin{array}{l}80 \\
(22.5)\end{array}$ & $\begin{array}{l}75 \\
(21.1)\end{array}$ & $\begin{array}{l}70 \\
(19.7)\end{array}$ \\
\hline
\end{tabular}

\footnotetext{
There are overlaps with some isolates harbouring more than one PMQR gene.
}

\section{Association between quinolones resistance and ESBL, AmpC beta-lactamase production}

There was a significant association between quinolone resistance and ESBL production in the isolates, $65(26.6 \%)$ of the quinolone-resistant isolates were ESBL-producers with an odd ratio of 10.2 while 34 (13.9\%) were AmpC-producers, odd ratio 5.7. (Table4) 
Table 4. Association between resistance to quinolones in isolates and ESBL, AmpC beta-lactamase production

\begin{tabular}{|c|c|c|c|c|c|}
\hline & \multicolumn{2}{|c|}{ Quinolone } & \multirow{3}{*}{$\begin{array}{l}\text { Total no of } \\
\text { isolates }\end{array}$} & \multirow{3}{*}{ Odd ratios } & \multirow{3}{*}{ Statistics } \\
\hline & Resistant $(n=244)$ & Susceptible ( $\mathrm{n}=146)$ & & & \\
\hline & $\%$ & $\%$ & & & \\
\hline \multicolumn{6}{|l|}{ ESBL } \\
\hline Producers & $65(26.6)$ & $5(3.4)$ & 70 & 10.2 & $x^{2}=33.426$ \\
\hline Non-producers & $179(73.4)$ & $141(96.6)$ & 320 & & $p<0.001^{*}$ \\
\hline Total & $244(100)$ & $146(100)$ & 390 & & \\
\hline \multicolumn{6}{|l|}{ AmpC } \\
\hline Producers & $34(13.9)$ & $4(2.7)$ & 38 & 5.7 & $\chi^{2}=12.031$ \\
\hline Non-producers & $210(86.1)$ & $142(97.3)$ & 352 & & $p<0.001^{*}$ \\
\hline Total & $244(100)$ & $146(100)$ & 390 & & \\
\hline
\end{tabular}

\section{Discussion}

Our study showed Escherichia coli, Klebsiella spp and Pseudomonas aeruginosa as the most predominant causes of Gram negative infections in our environment. Escherichia coli and Klebsiella spp. were the commonest causes of UTI while Pseudomonas aeruginosa was the commonest cause of wound infection. About two-third $(n=256 ; 67 \%)$ of the patients were on hospital admission, thus some of the infections were hospital acquired. A high level of resistance to common antibiotics in routine use were observed and most importantly, there is high level quinolone resistance among the isolates with at least one in every two Gram-negative bacilli isolated being quinolone-resistant. Resistance to the first generation quinolone; nalidixic acid (62.6\%) was found to be higher than to the fluoroquinolones $(51.0 \%$ for ciprofloxacin, $52.1 \%$ for ofloxacin and $52.3 \%$ for norfloxacin). Qunolone resistant isolates were also found to be resistant to most of the antibiotics in other classes used in this study; aminoglycoside, penicillins and cephalosporins except for imipenem, a carbapemem. This is in agreement with studies which showed flouroquinolone-resistant strains are usually resistant to multiple antimicrobials, ${ }^{21}$ as 
quinolone-resistance specific mechanisms evolved on a background of existing mechanisms conferring resistance to multiple classes of antibiotics. ${ }^{2}$

The highest level of resistance to quinolones were found in isolates of Escherichia coli, Klebsiella spp and Pseudomonas aeruginosa, as these organisms were also the commonest causes of infections which are routinely treated with quinolones in the patients. Only an isolate of Salmonella spp was resistant to the four quinolones used in this study, this is in keeping with studies done on resistance to quinolones in Salmonella spp in Africa which found ciprofloxacin-resistant salmonellae to be uncommon in humans. ${ }^{21}$

In addition to high level quinolone resistance found in this study, there was a wide distribution of plasmidmediated quinolone resistant (PMQR) genes among the quinolone-resistant isolates which is likely responsible for the high level of resistance to quinolones found in these isolates. Up to $180(73.8 \%)$ of these isolates harboured one PMQR gene or more of these genes while no PMQR gene was detected in 64 $(26.2 \%)$ of the isolates resistant to quinolones. Of all the Escherichia coliisolates which accounted for $31 \%$ of the total isolates, 84 were resistant to quinolones and harbour one or more PMQR gene, more prominently $\operatorname{aac}\left(6^{\prime}\right)-l b-c r$ which was found alone or in addition to other PMQR genes in 33 of the E.coli isolates representing $39.3 \%$ of the total E.coli found to be resistant to quinolones. Almost half $(34,47.2 \%)$ of Klebsiella spp isolated also had qepA gene alone or in additon to other PMQR especially oqxAB, which was found to be more prevalent in Klebsiella spp, this was not suprising as oqxAB genes are naturally present on the chromosome of $K$. pneumoniae with different levels of expression. ${ }^{11}$

Aac (6')-Ib-cr was also predominant in $P$. aeruginosa, found in $12 \%$ of the whole $P$. aeruginosa isolated. The only spp of salmonella found to be resistant to quinolone had oqxAB gene. The most prevalent PMQR gene overall was qepA found in $32.8 \%$ of the whole quinolone-resistant isolates. Though, target protection mechanism (qnrproteins) were the first to be discovered, this study found more recent determinants appearing to be more successful with efflux mechanisms ( $q e p A$ and oqxAB) and drugmodifying (acetylating; $\left.a a c\left(6^{\prime}\right)-l b-c r\right)$ mechanism being the most common determinants of resistance than the qnr proteins. This is similar to findings from studies done across regions in sub-sahara Africa which also found a high prevalence of PMQR determinants among quinolone resistant organisms with efflux pumps and drug-modyfying mechanisms being more common than target protection mechanism. $^{21}$

The few studies available on PMQR in Nigeria have also shown a high prevalence of the efflux and drug modifying genes in clinical isolates from humans, ${ }^{14,16,21,29}$ also contrary to earlier reports and distribution of target site protection, drug-modifying and efflux determinants are rather of greater significance. Studies done outside the continent also showed a high prevalence of PMQR in clinical isolates. The PMQR genes were found to be absent in some isolates which were resistant to quinolones, these isolates probably have chromosomal mutations in DNA gyrase and topoisomerase IV leading to the resistance observed, also there might be more plasmid-mediated mechanisms which have only been recent described ${ }^{30}$ or not yet been descibed.A significant association between quinolone resistance, ESBLs and AmpC-production was found in this study. Of all the quinolone-resistant isolates, $26.6 \%$ were 
ESBLs producers while $13.9 \%$ were AmpC producers and these represents $92.9 \%$ and $89.5 \%$ of the total ESBLs and AmpC-producing bacilli respectively. This is in keeping with earlier studies done which established a close association between PMQR determinants, extended-spectrum and AmpC-type beta lactamases. ${ }^{11,31-39}$ This is probably because most of the genes involved are usually carried on the same plasmid, and can result in multidrug resistance.

Although, it has been advised that the use of fluoroquinolones be restricted due to its associated increased risk in tendon rupture especially in males, the elderly and when in use with corticosteroids ${ }^{40}$, the drugs are still in common use as first line in our envirnment for management of various infections. The high level quinolone resistance found from this study and the known associated risks calls for a review of the use of this drugs as first line drugs.

\section{Conclusions}

This study showed there is a high level quinolone resistance, with at least one in every two Gram-negative bacilli isolated being quinolone-resistant and up to $73.8 \%$ of these quinolone-resistant isolates harboured one or more PMQR genes. Though, drug-protection mechanism were the first to be discovered, more recent determinants appear to be more successful with different efflux and drug modifying (acetylating) mechanisms being the most common determinants of resistance. There is also a high level of expression of other determinants of broad spectrum antibiotics resistance as well as resistance to other antibiotics in common use in our environment.

We recommend a review of the use of quinolones as first line drugs in management of patients and a continuos resistance surveillance and antimicrobial stewardship to guide appropriate use of antibiotics.

\section{List Of Abbreviations}

PMQR Plasmid-mediated quinolone resistance

PCR Polymerase chain reaction

DNA Deoxyribonucleic acid

OAU Obafemi Awolowo University

OAUTHC Obafemi Awolowo University Teaching Hospitals Complex

CLED Cystein lactose electrolyte deficient medium

CSF Cerebrospinal fluid

ESBL Extended spectrum beta-lactamase

SPSS Statistical Package for the Social Sciences

Page 12/16 


\section{Declarations}

\section{Ethical Approval}

Ethical approval was obtained from the Research and Ethics Committee of the OAUTHC, lle-lfe for the study (protocol number ERC/2016/01/09).

Consent for Publication

Not applicable

\section{Competing Interests}

The authors declare that they have no competing interests.

\section{Funding}

The funding for this work was sorely by the authors.

\section{Authors' Contributions}

AR was involved in sample collection, processing, analysis, Interpretation of data and a major contributor in writing the manuscript. B. analysed and also interpreted data. OA conceived the study and was also a contributor in writing the manuscript. All authors read and approved the final manuscript.

\section{Acknowledgements}

The authors acknowledge the Management and Staff of Obafemi Awolowo University Teaching Hospitals Complex, lle-lfe especially those of the Department of Medical Microbiology and Parasitology Department.

\section{References}

1. Hooper DC, Strahilevitz J. Quinolones. In: Mandell GL, Bennett JE, Dolin R, editors. Mandell, Douglas, and Bennett's principles and practice of infectious Diseases. 7th ed: Churchill livingstone Elsievier. p. 487-510.

2. Hernandez A, Sanchez MB, Martinez JL. Quinolone resistance: Much more than Predicted. Frontiers in Microbiology 2011. 2011;2. 
3. Torok E, Moran E, cooke F. Global antibiotic use.Oxford handbook of infectious diseases and microbiology. 1st edition ed.

4. Linder J, Huag E, Steinman M, Gonzales R, Stafford R. Fluoroquinolone prescribing in the united states: 1995 to 2002. The American Journal of Medicine. 2005;118:259 to 68.

5. Ohene S-A, BM, Ojo J, Toonstra A, Awudi D. Klatser P Extra-pulmonary tuberculosis: A retrospective study of patients in Accra, Ghana. PLoS ONE 2019;14(1).

6. Ramirez-Lapausa M, Noguerado-Asensio AM-S,A. Extrapulmonary tuberculosis: an overview. Rev Esp Sanid Penit. 2015;17:3-11.

7. Jacoby G, Cattoir V, Hooper D, Martínez-Martínez L, Nordmann P, Pascual A, et al. qnr gene nomenclature. Antimicrob Agents Chemother. 2008;52:2297-9.

8. Poirel L, Rodriguez-Martinez J, Mammeri H, Liard A, Nordmann P. Origin of plasmid-mediated quinolone resistance determinant QnrA. Antimicrob Agents Chemother. 2005;49:3523-5.

9. Jacoby $G$, Walsh K, Mills D, Walker V, Oh H, Robicsek A, et al. qnrB, another plasmid-mediated gene for quinolone resistance. Antimicrob Agents Chemother. 2006;50:1178-82.

10. Ade SHA, Tre'bucq A, Ade G, Agodokpessi G, et al. National Profile and Treatment Outcomes of Patients with Extrapulmonary Tuberculosis in Be'nin. PLoS ONE. 2014;9(4).

11. Strahilevitzl J, Jacoby G, Hooper DC, Robicsek A. Plasmid-Mediated quinolone resistance: a Multifaceted Threat. American society for Microbiology Clinical Microbiology Reviews. 2009;22:66489.

12. Jacoby G. Mechanisms of Resistance to Quinolones. Clinical infectious Diseases. 2005;41:120-S6.

13. Lamikanra A, Crowe JL, Lijek RS, Odetoyin BW, Wain J, Aboderin AO, Okeke IN. Rapid evolution of fluoroquinolone resistant Escherichial coli in Nigeria is temporally asssociated with fluoroquinolone use. BMC Infect Dis. 2011;11:312.

14. Ogbolu DO, Daini OA, Ogunledun A, Alli AO, Webber MA. High Levels of Multidrug Resistance in Clinical Isolates of Gram -Negative pathogens from Nigeria. Int J Antimicrob Agents. 2011;37(1):626.

15. Aibinu I, Aednipekun E, Odugbemi T. Emergence of Quinolone Resistance amongst Escherichia coli strains isolated from clinical infections in some Lagos State Hospitals, in Nigeria. Nigeria Journal of Health Biomedical Sciences. 2004;3:73-8.

16. Ogbolu DO, Alli AO, Anorue MC, Daini OA, Oluwadun A. Distribution of plasmid-mediated quinolone resistance in Gram-negative bacteria froma tertiary hospital in Nigeria. Indian J Pathol Microbiol. 2016;59(3):322-6.

17. Nkemngu N. Susceptibility patterns of Salmonella enterica serovar Typhi to 10 antibiotics in Cameroon. 6th international conference on Typhoid fever and other salmonelloses; Guilin, China2005.

18. Opitan J, Newman M, Nsiah-Poodoh O, Okeke I. Vibrio cholerae 01 from Accra, Ghana carrying a class 2 integron and the SXT element. J Antimicrob Chemother. 2008;62:929-33. 
19. Namboodiri S, Opitan J, Lijek R, Newman M, Okeke I. Quinolone resistance in Escherichia coli from Accra, Ghana. BMC Microbiol. 2011;11:44.

20. Aibinu IE, Adenipekun EO, Nwaka DC, Adelowotan AO, Ajekigbe AT, Adeyemi OF, et al. Emmergence of Cross-Resistance to Fluoroquinolones in Gram- Negative isolates from Cancer infections in a Tertiary Hospital in Nigeria. The Journal of American Science. 2008;4(4).

21. Chattaway MA, Aboderin AO, Fashae K, Okoro CK, Opintan JA, Okeke IN. Fluoroquinolone-Resistant Enteric Bacteria in Sub-Saharan African: Clones, Implications and Research Needs. Front Microbiol. 2016;7:558.

22. Mandell G, Bennett J, Dolin R. Urinary tract infections. Mandell, Douglas, and Bennett's principles and practice of infectious Diseases. Seventh ed: Churchill livingstone Elsievier. p. 971.

23. D.C L. Textbook of Diagnostic Microbiology: Biochemical Identification of Gram-Negative Bacteria. 5 ed: ELSEVIER; 2015.

24. Organization WH. Basic Laboratory Procedures in Clinical Bacteriology. 2 ed. Geneva2003.

25. Institute CaLS. Performance standards for antimicrobial susceptibility testing Wayne, PA; USA: 2009 Contract No.: M100-S19.

26. Bauer A, Kirby W, Sherris J, Turck M. Antibiotic susceptibility testing by a standardized single disk method.. Am J clin Pathol. 1966:493-6.

27. Black JA, Moland ES, Thomson KS. AmpC Disk Test for Detection of Plasmid-Mediated AmpC BLactamases in Enterobacteriaceae Lacking Chromosomal AmpC B-Lactamases. J Clin Microbiol. 2005;43(7):3110-3.

28. Ciesielczuk H, Hornsey M, Choi V, Wooford N, Wareham D. Development and evaluation of a multiplex PCR for eight plasmid mediated quinolone resistance determinants. J med Microbiol. 2013;62:1823-7.

29. Ezeh PA, Tende M, Bolaji RO, Olayinka BO, Menegbe BY, Igwe JC. Prevalence of Aac(6')-lb-cr and Qepa Genes among Quinolone Resistant Uropathogens isolated from Asymptomatic female students of a Northern University of Nigeria. Clin Microbiol 2017. 2017;6(5).

30. Albornoz ETN, De Belder D, Gomez S, Martino F, Corso A, Melano RG, Petroni A,. qnrE1, a Member of a New Family of Plasmid-Located Quinolone Resistance Genes, Originated from the Chromosome of Enterobacter Species. Antimicrobial agents abd Chemotherapy. 2017.

31. Jiang Y, Zhou Z, Qian Y, Wei Z, Yu Y, Hu S, et al. Plasmid-mediated quinolone resistance determinants qnr and aac $\left(6^{\prime}\right)$-lb-cr in extended-spectrum $\beta$-lactamase-producing Escherichia coli and Klebsiella pneumoniae in China. J Antimicrob Chemother. 2008;61:1003-6.

32. Yang $H$, Chen $H$, Yang $Q$, Chen $M$, Wang $H$. High prevalence of plasmid-mediated quinolone resistance genes qnr and aac $\left(6^{\prime}\right)-\mathrm{lb}-\mathrm{cr}$ in clinical isolates of Enterobacteriaceae from nine teaching hospitals in China. Antimicrob Agents Chemother. 2008;52:4268-73.

33. Pai H, Seo M, Choi T. Association of QnrB determinants and production of extended-spectrum $\beta$ lactamases or plasmid-mediated AmpC $\beta$-lactamases in clinical isolates of Klebsiella pneumoniae. Antimicrob Agents Chemother. 2007;51:366-8. 
34. Szabo D, Kocsis B, Rokusz L, Szentandrassy J, Katona K, Kristof K, et al. First detection of plasmidmediated, quinolone resistance determinants qnrA, qnrB, qnrS and aac $\left(6^{\prime}\right)-\mathrm{lb}-\mathrm{cr}$ in extended-spectrum $\beta$-lactamase (ESBL)-producing Enterobacteriaceae in Budapest, Hungary. J Antimicrob Chemother. 2008;62:630-2.

35. Gay K, Robicsek A, Strahilevitz J, Park C, Jacoby G, Barrett T, et al. Plasmid mediated quinolone resistance in non-Typhi Salmonella. Clin Infect Dis. 2006;43:297-304.

36. Poirel L, Pitout J, Calvo L, Rodriguez-Martinez J, Church D, Nordmann P. In vivo selection of fluoroquinolone-resistant Escherichia coli isolates expressing plasmid-mediated quinolone resistance and expanded-spectrum beta-lactamase. Antimicrob Agents Chemother. 2006;50:1525-27.

37. Coque T, Novais A, Carattoli A, Poirel L, Pitout J, Peixe L, et al. Dissemination of clonally related Escherichia coli strains expressing extended-spectrum $\beta$-lactamase CTX-M-15. Emerg Infect Dis. 2008;14:195-200.

38. Robicsek A, Jacoby G, Hooper D. The worldwide emergence of plasmid-mediated qunolone resistance. Lancet infect Dis. 2006;6:629-40.

39. Gourdarzi M, Azad M, Seyedjavadi SS. Prevalence of Plasmid-Mediated Quinolone Resistance Determinants and oqxAB Efflux Pumps among Extended-Spectrum B-Lactamase Producing Klebsiella pneumoniae Isolaed from Patients with Nosocomial Urinary Tract Infections in Tehran, Iran. Scientifica. 2015;7.

40. Morales DR, Slattery J, Pacurariu A, et al. Relative and Absolute Risk of Tendon Rupture with Fluoroquinolone and Concomitant Fluoroquinolone/Corticosteroid Therapy: Population-Based Nested Case-Control Study. Clin Drug Investig. 2019;39:205-13. https://doi.org/10.1007/s40261018-0729-y. 